\title{
17
}

\section{Timing and Climate: Rainfall Variability in Northern Australia}

\author{
Chris O’Brien, Sara Beavis, Andrew Campbell \\ and Tom Griffiths
}

People have observed the skies over Northern Australia for millennia. First, Indigenous peoples garnered knowledge linking land, seas and sky. Then, the colonial invaders imported their own ways of seeing and knowing. The two have long existed side by side and the dominance of Western knowledge has, until recently, rendered Indigenous knowledge invisible beyond the Aboriginal population. Depending on your cosmology, we in the north have long experienced a common weather but different climates and seasons in the very same places.

Nevertheless, Western meteorology in Northern Australia has long been of remarkably high quality. The colonial Departments of Astronomy in the colonies of South Australia, Western Australia and Queensland saw to this before the establishment of the Commonwealth Bureau of Meteorology in 1908. The Bureau itself has seen to this since. The first systematic daily weather records for Darwin were taken in March 1869. Records for Katherine, Daly Waters and other NT locations soon followed. Several lines of telegraph wire tied each of these 'outposts' to each other and to the already well-developed meteorological networks in South Australia, Victoria and New South Wales (NSW), and through them to the broader networks throughout the British Empire. Now they bequeath a legacy of millions of pieces of 'local' weather data. Despite this, responding to the federal government's green paper on northern development, the Australian 
Academy of Science argued that climate variability in Northern Australia is still so little understood that this deficiency is a barrier to the northern development agenda (Australian Academy of Science, 2014).

How can this be? Millions of data! In recent decades, the Bureau has produced maps of rainfall variability across Australia. As long ago as 1916, the distinguished Geographer Griffith Taylor did the same. During the 1980s, climatologists investigated the timing of both the Wet Season and the Monsoon in Northern Australia (Nicholls et al., 1982; Holland, 1985), albeit with a statistical rather than an analytical historical approach. One answer is that Indigenous knowledge was pushed aside. But there are other important answers in the way we do meteorology, which is one focus of this paper. We will outline historical variability in rainfall for Darwin, Pine Creek, Katherine, Daly Waters, Wyndham, Broome and Burketown. Here we demonstrate variability by showing that the timing of rainfall across the north, historically, has frequently and consistently varied from year to year over a 70 -year period. We also look at variability in streamflows in the Elizabeth and Daly river systems. This history illustrates the importance of timing, and volumes, and that time matters on numerous scales. We finish with a discussion of policy implications, especially in light of expected climate change. Variability and cycles are not evidence against anthropogenic climate change; variability is exacerbated by and cycles interact with a warming global atmosphere.

\section{Ideas}

Aboriginal meteorology is characterised by interconnections between events on the land, in rivers and seas and, of course, in the sky. Change of season is not related to the calendar. Clusters of natural events mark changes of season-when certain animal behaviours match particular appearances of plants, when these are accompanied by specific known winds, or kinds of rain or even patterns of rainfall. In Northern Australia, these vary from community to community. So, ideas of season and climate are place based and markedly local. Not being bound to the calendar, these concepts of season allow for variability from year to year, in stark contrast to Western scientific understandings of season. North Australia's Aboriginal and Torres Strait Islander peoples conceive of season and climate in holistic, ecological terms. ${ }^{1}$

1 For more see O’Brien (2016). 
Two compelling ideas infuse the scientific study of weather and climate. Both have somewhat sidelined variability in the meteorological literature. First is the notion of the 'clockwork climate' (O'Brien, 2014), the elegant idea that weather and seasons happen in a timely manner, year after year. The oldest surviving expression comes from the oldest farmer's almanac Hesiod's Works and Days dating to the eight century BCE. More examples abound in the corpus of Greek and Roman literature. More than 2,000 years ago, the idea of the four seasons inextricably linked to what we know as the rotation of Earth on its axis became established. The atmospheric clock has long appeared to have a mechanism. The concept has seemed to explain what people experienced. This idea made sense to people in modern times and as Europeans voyaged to other climates they formulated the notion of the wet/dry seasonal dyad for the tropics. Jan Huyghen van Linschotten and Edmund Halley were among early promulgators of this idea during the seventeenth century, though they defined the seasons by wind regimes or monsoons. William Dampier was the first to explicitly identify wet and dry seasons for the tropics. Versions of the clockwork climate for the tropics and temperate zones spread through nautical guides, almanacs and, later, popular press. Not merely an idea, this was something people lived. It organised trade, travel, farming, commerce, festivals for centuries. It shaped individual and communal life and was integral to how people made sense of the natural and cultural world. Empirical observation here and throughout Australia was organised by this powerful concept, not used to test its veracity. Unsurprisingly, Darwin's weather-watcher extraordinaire J. A. G. Little, in 1902, said of the Top End's weather that 'the different changes of these seasons are so uniform and regular that they may be predicted to almost a day' (Little, cited in Taylor, 1918, p. 70). Even now, local media in Darwin effectively do the same thing every 1 October when they declare a change of season irrespective of the weather. Weather has long been seen to have an almost precise regularity, more so than empirical evidence supports. Through this conceptual lens, variability is sometimes difficult to see as a significant aspect of climate.

The second idea is virtually a statistical version of the first. Before meteorology incorporated hydrodynamics and thermodynamics in the first quarter of the twentieth century, it was, practically, a statistical discipline. After the 'physical turn', averages for rainfall, temperature, humidity and any element that can be measured and enumerated remain at the core of weather and climate study. But means have long borne a compelling 
meaning. In the early 1800s, Belgian Astronomer Royal Adolphe Quetelet argued that in a distribution of measurements of multiple observations, individual readings contain error but the mean, provided sufficient measurements - this reflects reality (Hacking, 1990). Philosopher Ian Hacking showed in his work Taming of Chance that this concept became a template for understanding measurable phenomena throughout the nineteenth century and for much of the twentieth. It is certainly evident in Australian weather records through to the 1980s. The mean indicated true rainfall, temperature etcetera and a mean of means revealed climate. Variation was understood as deviation from an idealised norm. Reality/ normality was indicated by a point, not ranges or distributions. Through these understandings, the statistical practices of meteorology occluded variability. In a dominant mechanistic metaphysics where weather and climate were seen as repeating on an annual basis according to Earth's rotation on its axis and, hence, tied to the calendar, climatic variability was often seen as variation-sets of singular aberrations not part of an elemental pattern.

\section{Realities}

Experience, however, often challenges the conceptual. In the midnineteenth century, George Goyder grappled with rainfall variability in South Australia in drawing a line to demarcate places of reliable rainfall from those of unreliable rains. During the 1880s, Charles Todd and his counterparts in NSW, Victoria and India corresponded about weather teleconnections ${ }^{2}$ between Australia and India after observing remarkable rainfall variability. Geographer Griffith Taylor calculated rainfall variability across Australia in the 1910s and, with perhaps the most comprehensive understanding of Australia's climates at the time, argued that this continent had a limited carrying capacity. Griffith Taylor and Goyder bore inconvenient truths that were sidelined by politics. The teleconnections studied by Todd and colleagues were the start of a long process that eventually led to the revelation of El Niño-Southern Oscillation (ENSO). But since there was then no explanatory mechanism for their observations, they were seen as deviations rather than as part of a variable climate that worked over cycles of 3-8 years.

2 Teleconnections are large-scale climatic anomalies in air pressure and atmospheric pressure usually manifesting in prolonged periods of drought or flood across a variety of large-scale regions. 
Variability is more visible now. But it is studied in limited ways. Variability has been applied to volumes. The formula is 90th percentile to 10th percentile readings divided by the median. This is useful but conceals temporal variability. When do rains come? What are the consequences on the land? These are issues that play out on a variety of timescales, not just the calendar month or calendar year at the core of so much weather and climate research. To make sense of temporal variability, this chapter notes the 10th and 90th percentiles of the timing of a particular milestone. So, if the data set extends to a period of 70 years, the date by which the seven earliest and from which the seven latest instances occur is noted. With records spanning 50 years, the corresponding times for the five earliest and the five latest are highlighted. Where seasons are defined as lasting six months, we posit that a difference of one month is a reasonable mark of variability. The greatest consequences of variability are ecological-the critical points at which timing of rain would cause significant impact differ from plant to plant, animal to animal, crop to crop and season to season. Given this, it is more useful now to outline the variability rather than calculate any one-size-fits-all statistics. In any case, the need to look at timing of rains and variability is evident.

First, a word on the data. ${ }^{3}$ To avoid confounding with rainfall variability, most data date to when anthropogenic climate change is understood to have had minimal influence. Climatologists have no standard definition of the onset of the wet (Nicholls et al., 1982). To examine rainfall variability then, across time, we look at four rainfall milestones. The first is simply the timing of first rains, which is important enough to feature in north Australia-based fiction of authors such as Xavier Herbert and Jeannie Gunn. Rainfall histories reveal a temporal variability at odds with the clockwork climate. Between 1871 and 1941, the earliest seven first rains in Darwin came before 15 July and the latest seven from mid-October, with a range from 1 July to 16 November. Three months separates the earliest 10 per cent from the latest 10 per cent.

Usually comprising numerous rain events, the date when $50 \mathrm{~mm}$ of cumulative rain from the start of the seasons is a more reliable measure. Variability is still evident; the earliest seven came on or before 7 October and the latest seven from 27 November, three of which were well into

3 Unless otherwise stated, all data is from the Bureau of Meteorology, Climate Data Online. 
December. Seven weeks span the differences between the earliest and latest 10 per cent of instances. The range runs from 24 September to 13 December.

We still see marked variability for the timing of $100 \mathrm{~mm}$ cumulative rain; the earliest came on 6 October and the latest on 26 December, with the seven earliest by 25 October and the seven latest from 8 December. This is still a big difference in timing - six weeks between the earliest 10 per cent and the latest 10 per cent. Crucially, this is six weeks at a time of maximum insolation and evaporation, which gives such variability enormous ecological significance. Figure 17.1 illustrates the historical variability of this marker. Last rains are also variable in timing. The earliest seven (or 10 per cent) came mid-April or earlier and the latest seven (or 10 per cent) from mid-June, ranging from 9 April 9 to 30 June.

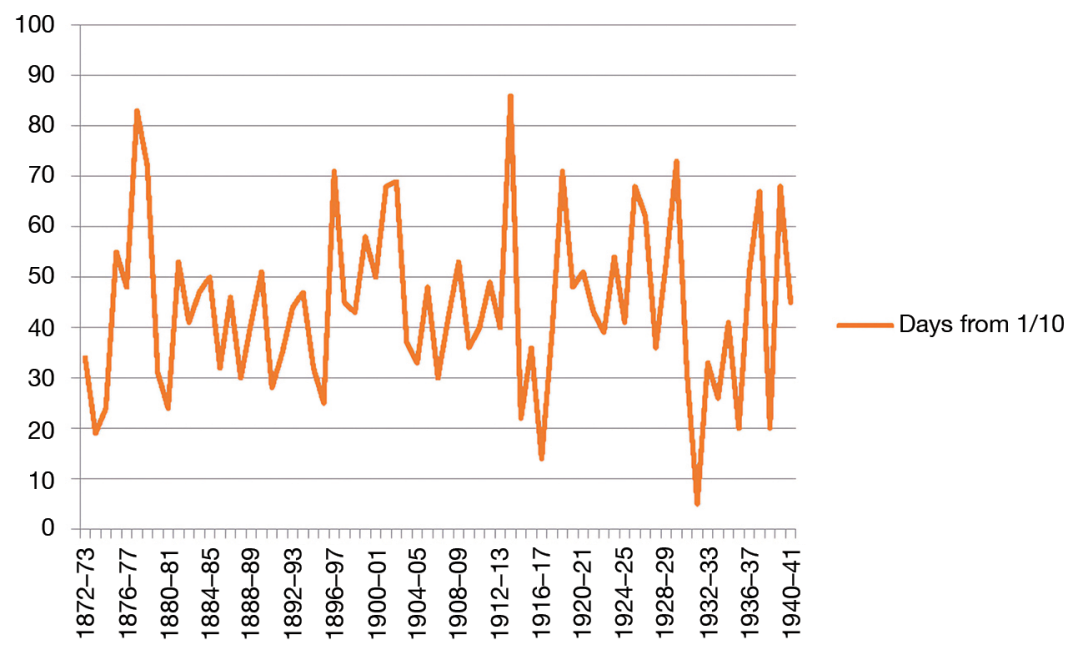

Figure 17.1: Darwin Post Office, temporal variability $100 \mathrm{~mm}$ cumulative rains.

Note: The $x$-axis indicates years, the $y$-axis the number of days from 1 October that the $100 \mathrm{~mm}$ cumulative volume was reached. Defining wet season onset as the date when $100 \mathrm{~mm}$ of rain has been recorded we see large variability in its timing and that it frequently happens long after 1 October.

Source: Chris O'Brien, original research.

Records across the north tell the same story.

The timing of rain has varied remarkably from one year to another at Pine Creek, $250 \mathrm{~km}$ inland from Darwin. Between 1890 and 1941, the first rains come as early as 1 July and as late as 6 November. The earliest 
five occasions happened on or before 9 July and the latest five on or after 29 October. The $50 \mathrm{~mm}$ cumulative mark was reached as early as 26 September and on five occasions had been reached by 12 October. Five times it came on or after 24 November, with the latest being 18 December. The range for the $100 \mathrm{~mm}$ cumulative mark is 8 October to 28 December, with the five earliest happening by 22 October and the five latest from 9 December onwards. Rain fell as late as 29 June, with the five latest occasions being on or after 17 June. Yet, there were five years when rains had stopped by $28 \mathrm{March}$, one of which saw last rains on 14 March. For all milestones, the differences between the earliest and latest 10 per cent of instances was at least six weeks and, more typically, more than two months.

Rainfall at Daly Waters, $600 \mathrm{~km}$ south of Darwin, showed similar year on year differences between 1880 and 1941. First rains came as early as 1 July and as late as 13 November. On the six earliest occasions, the six earliest rains (10 per cent) had fallen by 12 July and the six latest on or after 31 October. In six of these years, the $50 \mathrm{~mm}$ cumulative mark for rainfall had been reached by 7 October and during another six it was not reached until 8 December or after, with a range of 27 August to 8 January. The $100 \mathrm{~mm}$ cumulative mark came as early as 4 October and as late as 25 February. Six times this happened by 15 November and another six not until 29 December or after. Last rains have fallen as late as 30 June and rain has ceased as early as 25 February. Six times rains have stopped as early as 18 March and six times they have come on 21 June or later. On each measure, the earliest and latest 10 per cent of instances have happened at least two months apart from each other.

Temporal variability is clear from records taken at Burketown, in Queensland's Gulf Country, between 1888 and 1941. For first rain, the range is 2 July -2 November with the earliest five, or 10 per cent, by 24 July and the latest five from 14 November onwards. For the $50 \mathrm{~mm}$ cumulative mark, five times was reached by 12 November and five times on or after 3 January, ranging from 8 October -26 January. For five years during this period, $100 \mathrm{~mm}$ of accumulated rain had fallen by 27 November, once occurring as early as 13 November. In five years, this point was not reached until 27 January or later and once as late as 19 February. Last rain fell as early as 21 February and as late as 30 June. Five times it had fallen by 21 March, another five it came on 22 June or later. Again, the typical difference between the earliest and latest 10 per cent of instances was two months. 
Between 1898 and 1941, rainfall at Wyndham, in the north-east Kimberley, shows something similar. First rains came as early as 1 July, on four occasions (10 per cent) coming by 16 July. First rains have fallen as late as 11 November, and 6 November or later in four years. In four years, $50 \mathrm{~mm}$ of rain had accumulated by 7 November. Four other years saw this not happen until 18 December or later, ranging from 9 October to 10 January. The $100 \mathrm{~mm}$ mark was reached as early as 14 November and as late as 7 February. Four times this happened by 28 November and four times on or after 10 January. In four years, last rains have come by 2 April, and another in four from 24 June, with a range from 15 March to 26 June. For all milestones, the difference between the earliest and latest 10 per cent of occurrences is six weeks or longer.

These indices tell a story largely untold in the meteorological literature of the time. The timing of rain is subject to enormous temporal variability across Northern Australia. Rainfall records contradict received ideas of the region's climates. It is wrong, however, to infer from these records that wet seasons are necessarily longer than people have thought, as implied by first rains in July and last rains in June. First and last rains are singular events. In a place of such intense insolation and potent evaporation it is overall patterns of rain - the shape of seasons - that matters ecologically. Regrettably, determining these shapes is beyond the scope of this chapter. The natural environment is dynamic and contingent. Organisms have slowly evolved to function within particular ranges and these relate to timing and duration. In a place where solar radiation bakes the environment with fierce intensity, follow-up rains matter as much as volumes. A season with recurrent periods of rain will create a remarkably different environment to one with only one brief burst or one with long enough gaps between rain to desiccate the land. Statistics yield vital information but they smooth away these contingencies. History is about contingency, the particular and the uncertain and so is ideally suited to investigating the shapes of seasons and the complexities of weather, climate and the broader environment.

Policies that ignore rainfall variability are likely to be mugged by reality. Regrettably, amnesia has long characterised discussions about northern development. Historian Libby Robin (2007) devoted an entire chapter to this in her book How a Continent Created a Nation. Past failures are forgotten so crucial lessons go begging-chiefly that development needs to be geared to the ecological limitations of particular locales. Rainfall variability is integral to this. In a region where insolation is so fierce that even a modest delay in the timing of rain can be lethal for stock and crops, 
weeks actually matter. Successful policies must be sensitive to the decisive effects of rainfall variability across time and space throughout Northern Australia. Successful policies must incorporate hard-won knowledge that has been forgotten or ignored. They must also heed new work that identifies the historical intricacies of the region's ecologies. Unless weather and climate are properly understood — on a variety of timescales - they are likely to continue to undermine all large-scale initiatives, just as they have done throughout the post-invasion history of Northern Australia.

\section{Longer Cycles}

Climate variability also happens on much larger timescales. It occurs not only at seasonal but also interannual and decadal timescales as responses to the Indian Ocean Dipole and the ENSO. Less well known is a much larger oscillation in annual rainfall thought to occur over a 50-100year cycle. Kraus (1955) first noted this pattern in coastal NSW, where the latter part of the nineteenth century was wetter than the first half of the twentieth century. Later studies have shown that an increasingly wetter phase occurred in the second half of the twentieth century and it now appears that eastern and south-eastern Australia are entering the next drying phase now. Over approximately 100 years, there are alternating drying and wetting periods demarcated by tipping points at which a change occurs over a very short period of time. For these regions, phase change at those tipping points has been associated with severe, prolonged drought (the Federation and Millennium droughts) and major flooding in the 1950s. Plotting data for Katherine and Daly Waters (from 1900-2013), with overlays for Broome and Darwin (from 1941-2013), demonstrates a similar long-term oscillation, despite a short perturbation in the 1980s (see Figure 17.2). The tipping points for Northern Australia occurred around 1910 and 1971-74, a lag of approximately 15-20 years with eastern Australia. The first tipping point around 1910 reflected a change to drying that lasted until the early 1970s, when the next shift occurred to an increasingly wetter regime. Conditions are still wetting up, but if the lag with the eastern states is an indication then the next tipping point could be expected in the next 10 years. 


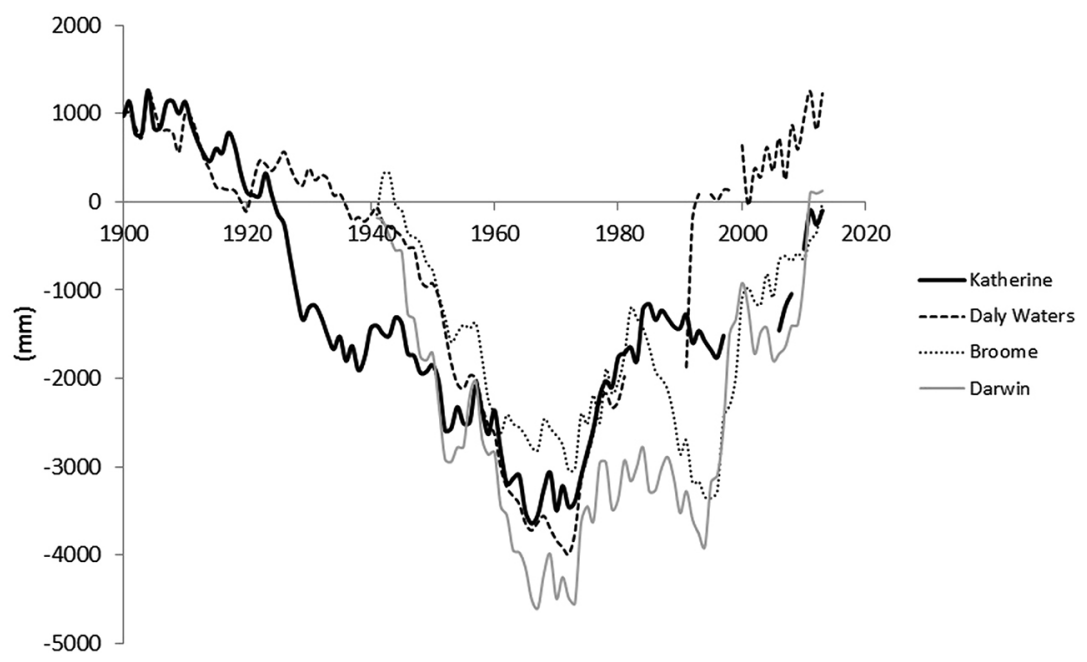

Figure 17.2: Long-term trends in rainfall for Katherine and Daly Waters (1900-2013) and Darwin and Broome (1940-2013).

Note: Figures along y-axis represent cumulative departure of annual rainfall from long-term annual mean. Increasingly wet conditions are depicted by a rising limb and increasingly dry conditions by a falling limb.

Source data: Bureau of Meteorology (2014); Sara Beavis, original research.

\section{Variable Rivers}

For Northern Australia, the percentage of rainfall that is converted to streamflow varies from 60 per cent along the coast to less than 3 per cent inland. Unlike in the Murray-Darling, most runoff is generated in the lower catchment rather than in upland regions. Monsoonal troughs and depressions associated with cyclones account for this. Therefore, rainfall patterns, regardless of temporal scale, are reflected in streamflow variability; higher flows occur during wet periods and lower or no flows during dry periods.

Hydrological gauging networks are less extensive and more recent than meteorological networks in Northern Australia. Nevertheless, 40 to 50 years of records illuminate the salient characteristics of two contrasting river systems in the Northern Territory, the Daly and Elizabeth rivers.

The iconic Daly River is one of the largest perennial streams in Northern Australia. With a total catchment area of over $53,000 \mathrm{~km}^{2}$, the Daly rises in the arid foothills of Arnhem Land and flows $-320 \mathrm{~km}$ into the Timor Sea. 
Estuarine conditions occur in the final $65 \mathrm{~km}$ as the river opens out into a typical funnel-shaped tide-dominated estuary surrounded by abundant tidal flats and salt marshes. Dry season flow is maintained by groundwater discharging from extensive limestone aquifers (the Cambrian Tindal Limestone and Ordovician Oolloo Dolostone), which recharge during the wet season, when some 92 per cent of annual streamflow occurs. This means that the river is flood dependent in the 'Wet' and groundwater dependent in the 'Dry'. These different water sources have distinct physicochemical properties that affect the nutrient load and primary production in the stream environment. The extreme seasonality also means that the upstream extent of tidal waters, and the associated salinity gradient from seawater to freshwater, varies over tens of kilometres depending on the volume of freshwater flowing down the system across the wet and dry seasons. High-value ecosystems have evolved that are dependent on these rhythmically changing environments, providing habitat to numerous reptile, fish and plant species, including the vulnerable pig-nosed turtle (Vallismeria nana) and the giant whip ray (Himantura dalyensis). Climate change will likely interfere with these sensitive rhythms.

Significant changes to these flow regimes in terms of the frequency and duration of wet season flood flows and dry season low flows will impact these ecosystems (Georges et al., 2002). With this in mind, the high interannual and interdecadal variability in flow that also mimics rainfall temporal patterns is also important for water-dependent biota at longer timescales.

The Elizabeth River flows into Darwin Harbour, draining a catchment of $-23,000 \mathrm{~km}^{2}$. The catchment includes extensive inter-tidal flats and groundwater-fed wetlands in the estuary and low-lying floodplain areas, agriculture, horticulture, urban, peri-urban and industrial land uses. Streamflow is highly seasonal with 98 per cent of annual flow occurring during the Wet and only 2 per cent during the Dry. Conditions of no flow or very low flows characterise the dry season throughout the non-estuarine reaches of the river system. Most of the wet season streamflow is derived from rainfall, with some contributions from groundwater discharging from underlying shallow Cainozoic laterite and Cretaceous sandstone aquifers. In the Dry, flows cease in all but the main river due not only to a lack of rain and surface runoff but the disconnection between the river and the underlying aquifer as groundwater levels drop, so that groundwater flows into the river system cease. 
Despite the differences in catchment area, geology, topography and mean annual rainfall, the Daly and Elizabeth river systems share some commonalities when long-term streamflow data are examined. Fifty-year records for the Daly River at Mt Nancar (gauging station \#G8140040) and Elizabeth River at Stuart Highway (gauging station \#G8150018) ${ }^{4}$ show that streamflow mimics climate at a range of scales. For example, rainfall anomalies (that is, the departure of annual rainfall from the long-term mean) closely correlate with the Southern Oscillation Index in both systems (see Figure 17.2). At seasonal scales (again, using longterm data), the distribution of rainfall and runoff follow similar patterns. Although the Daly is perennial, maintaining flows throughout the year, and the Elizabeth is seasonally ephemeral, both systems not only reflect rainfall dominance throughout the wet season but have a one-month lag in stream response to the beginning of the dry season and a twomonth lag at its end. This is due to the key role of surface-groundwater connectivity with groundwater continuing to discharge into the streams after the dry season commences, but with steady depletion of the aquifers and lowering of the water table. The very dry catchment conditions when the wet season breaks means that most rainfall infiltrates the soil or is partitioned into evaporation pathways. Until the catchment becomes saturated, streams continue to experience low flow conditions, and in the case of the Elizabeth River the stream and aquifer do not reconnect until sufficient recharge raises the water table to threshold levels.

Streamflow records are not yet long enough to determine whether these two river systems experience 50-100-year oscillatory patterns of rainfall. However, a very close correlation has been observed during the current phase of increasingly wetter conditions since 1992 to 1994.

Both of these systems are vulnerable to land use changes that divert rainfall that is naturally partitioned into streamflow and groundwater recharge. In recent decades, approximately 6 per cent of the total Daly River catchment has been cleared for agricultural land use, with an increase in the number of bore licences issued in areas undergoing development. Pressure to further develop agriculture will increase demand for groundwater extraction during the dry season. This risks reduced streamflows and consequent impacts on water quality, aquatic habitats and cultural values of the river system. In the Elizabeth River catchment, which is undergoing rural and peri-urban

4 From Bureau of Meteorology, Climate Data Online. 
development, bore data provide clear evidence of water table lowering in response to land use change over the last few decades. Reduced flows will impact water quality and also extend the period over which the river is dry. The hydrogeology of both catchments has been mapped (Verma, 2003; Tickell, 2005) and the ecological risks have been identified (Hart, 2004; Chan et al., 2012). However, a sound understanding of the sustainable yields of the aquifers is yet to be developed.

Policy must anticipate not only the smoothed, typical, expected and normalised aspects of climate, rivers and environment, but also the contingent and the possible, however unlikely. Policy needs to understand how particular improbabilities coalesce to create challenging realities. Historical understanding helps in numerous ways-it uncovers forgotten particulars, gives a sense of the range of the possible and tells of problems already faced and how people have or have not dealt with them. Crucially, history can show comprehensively how environmental events relate to each other and the contingencies under which these relationships develop. With climate change, a location's future may well be discontinuous with its past but continuous with the past of another place. In this case, history will be vital in helping people adjust to their changing future and anticipating policy challenges.

\section{Policy: Problems}

In discussing the policy implications of climate variability for Northern Australia, it is important to distinguish between three climatic phenomena:

- climate variability - the 'natural' variation in climatic parameters such as temperature and rainfall within and between years

- climate change-shifts in the long-term underlying conditions in parameters such as temperature and rainfall

- extreme weather events-including cyclones and severe storms, flooding rains, heat waves and droughts.

These phenomena are inter-related. The climate change we have been experiencing over the last century-accelerating in recent decadescreates a warmer atmosphere with a higher moisture content, which is inherently more volatile. This amplifies climate variability, disrupts traditional patterns of atmospheric and oceanic circulation, and increases the likelihood of extreme weather events. Extreme weather events are 
one artefact of climate variability. An analogy used in climate science is that of a dice that has been weighted such that warming conditions with associated weather patterns (e.g. droughts, storms, floods and heat waves) are much more likely than extremes of cold.

Projections from the CSIRO and Bureau of Meteorology's Monsoonal north cluster report (Moise et al., 2015) suggest that the following are probable in Northern Australia over coming decades:

- warmer temperatures on land and in the ocean, with a rise in days above $35^{\circ} \mathrm{C}$ in Darwin from 11 per year to 43 in a median year to over 74 per year in the warmest 10 per cent of years by 2030

- amplified variability - wetter Wets and drier Drys

- fewer but more severe cyclones, but with a 60 per cent increase in the intensity of severe storms by 2030 , and a higher proportion of Category 4 and 5 events

- rising sea levels (currently $7 \mathrm{~mm} /$ year off Darwin, but with the potential for step changes this century if the accelerating melt of the Greenland Ice Sheet continues).

The potential impacts of such changes in climatic conditions are likely to include:

- increased risk of vector-borne diseases

- potential changes in the range of weeds and pests (as more tropical conditions extend further south)

- increasing challenges in managing bushfire extent and intensity

- more pressure on water supplies towards the end of longer dry seasons

- greater risk of damage to human settlements, food, water and energy supplies and infrastructure during extreme events

- increased heat stress and ticks on cattle (20 per cent impact on beef production by 2030)

- greater risks of flooding and storm surge impacts such as erosion and salt water intrusion in coastal areas.

From a public policy perspective, this is a classic nest of intertwined wicked problems (Brown et al., 2010) characterised by technical complexity and uncertainty; large scales in space and time; a mix of social, economic and biophysical drivers; and contested issues among diverse stakeholders. These challenges encompass issues as diverse as public 
health and safety, water security, food production, fire management, transport logistics, energy supplies and networks and intensified pressure on infrastructure, particularly near the coast where most people live. The diagram in Figure 17.3 illustrates that different types of developments operate over a range of planning and decision horizons, and that planning for more than $2^{\circ} \mathrm{C}$ of warming and metre(s) of sea level rise needs to be transformational, rather than incremental.

As we move along the 100-year timeframe in Figure 17.3, the boundaries between climate change, climate variability and extreme weather events, and even between climate change adaptation and mitigation, blur. The overarching policy challenge has been described as managing the unavoidable (adaptation) while avoiding the unmanageable (mitigation). Long term, mitigation (reducing net greenhouse gas emissions) becomes a key plank of adaptation.

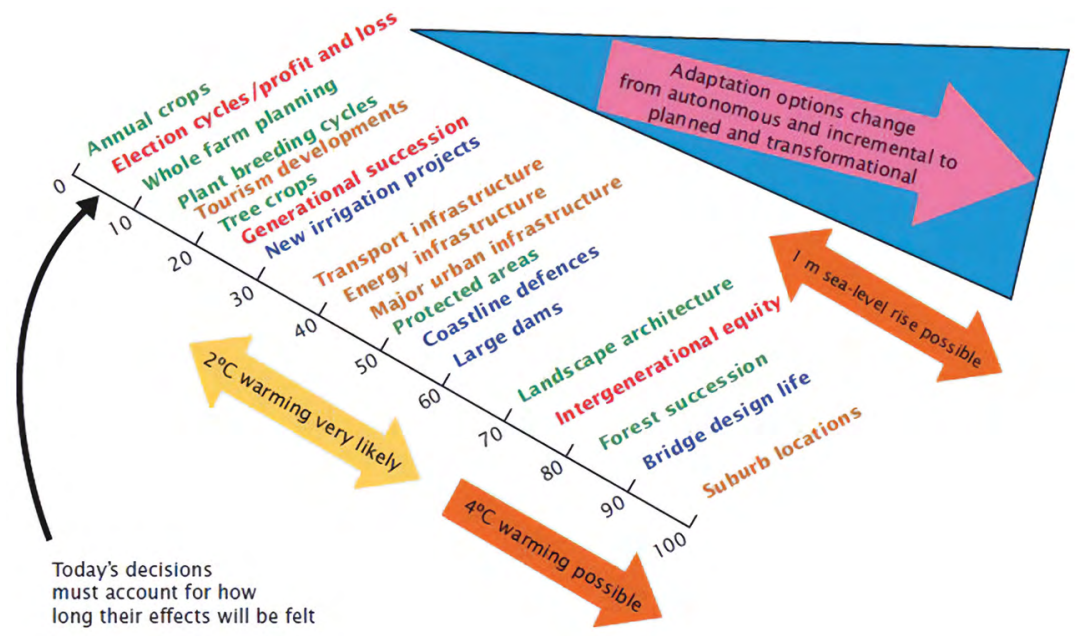

Figure 17.3: Climate change, adaptation options and human planning horizons.

Source: Cleugh et al. (2011).

\section{Solutions}

Climate change and its likely consequences demand sophisticated approaches to planning and risk management. A climate-smart policy menu for Northern Australia would likely include approaches to planning and development approval processes that: 
- are robust under a range of climate change and demographic scenarios

- build in resilience thinking (e.g. protect coastlines, improve habitat connectivity and buffering, protect refugia for threatened species)

- encourage carbon pollution mitigation in energy, transport and food systems

- encourage sustainable tropical design (carbon, water, energy, liveability, performance during and after extreme events) in the built environment at household, precinct and community levels

- safeguard productive soil and allow for increased food production and shorter supply chains

- manage demand for and facilitate recycling of water, nutrients and energy.

Policymakers must also adapt a place-based, rather than regional, approach. The historic variability of climate across the north means that rainfall and river flow vary not only from one place to another, but also from one year to another. Add climate change to this natural variability and regionalscale development such as the food bowl appears unviable. Agricultural development only has a chance if tied to the ecological particularities, limits and possibilities of individual places.

One question immediately presents itself: is this better done in a largely knowledge- and services-based economy, rather than in a resources-based economy?

The implications of a warming, more variable climate for Northern Australia are not all negative, nor are the policy implications all about defensive risk management. Developing low-carbon economies is one of the fastestgrowing economic opportunities globally. Anticipating, planning for and responding to extreme events and associated mass movements of people is also a rapidly growing industry. The inherent geological instability of Southeast Asia, particularly Indonesia, has implications for human settlements and infrastructure comparable to extreme climatic events. The tropical zone is the fastest-growing region of the world economy. Solutions developed for urban and remote communities in Northern Australia are likely to be applicable elsewhere in the tropics, even though Australia's tropics are more climatically variable than other tropical regions, creating export opportunities for knowledge, technologies and services. With astute planning and strategic investment in capacity and regional partnerships, Darwin could position itself as a Southeast Asian centre of 
excellence for low-carbon economies and for disaster risk management and response, attracting international private and public investment and selling expertise and services throughout Asia and beyond.

If we distil governance to its essence-how society shares risks, benefits and costs through space and time-then it is clear that the climate challenge is fundamentally a test for our systems of governance. At a macro level, the climate policy challenge is equally about how society sets policy directions and makes decisions, and what decisions are made by whom. Ideally, climate policy demands approaches_or at least core objectives and principles - that are bipartisan, extend beyond government to civil society and industry, and endure over multiple electoral cycles. Unfortunately, contemporary Australian politics is moving further and further away from this, for now. But it is also worth considering that many of the policy objectives canvassed above are worthwhile whether or not climate change is a factor. In any case, future prosperity relies on a deep understanding of the north's environmental history.

\section{References}

Australian Academy of Science. (2014, February). Submission to the Joint Select Committee on North Australia. Canberra, ACT. Retrieved from www.science. org.au/files/userfiles/support/submissions/2014/submission-joint-selectcommittee-northern-australia.pdf

Brown, V. A., Harris, J. A. \& Russell, J. Y. (Eds). (2010). Tackling wicked problems: Through the transdisciplinary imagination. London, England: Earthscan.

Bureau of Meteorology. (2014). Climate data online, daily and monthly rainfall data. Retrieved from www.bom.gov.au/climate/data/

Chan, T., Hart, B., Kennard, M., Pusey, B., Shenton, M., Valentine, E. \& Patel, S. (2012). Bayesian network models for environmental flow decision making in the Daly River, Northern Territory, Australia. River Research and Applications, 28(3), 283-301.

Cleugh, H., Stafford Smith, M., Battaglia, M. \& Graham, P. (Eds). (2011). Climate change: Science and solutions for Australia. Collingwood, Vic.: CSIRO Publishing.

Georges, A., Webster, I., Guarino, E., Jolly, P., Thoms, M. \& Doody, S. (2002). Modelling dry season flows and predicting the impact of water extraction on a flagship species - the pig nosed turtle (Carretochelys insculpta). Report prepared for the Northern Territory Department of Infrastructure Planning and Environment, Darwin. 
Hacking, I. (1990). Taming of chance. Cambridge, England: Cambridge University Press.

Hart, B. (2004). Environmental risks associated with new irrigation in Northern Australia. Ecological Management and Restoration, 5, 106-11.

Holland, G. J. (1985). Interannual variability of the Australian summer monsoon at Darwin: 1952-82. Monthly Weather Review, 114, 594-604.

Kraus, E. B. (1955). Secular changes of east-coast rainfall regimes. Quarterly Journal of the Royal Meteorological Society, 81, 430-439.

Moise, A., Abbs, D., Bhend, J., Chiew, F., Church, J., Ekström, M., ... Whetton, P. (2015). Monsoonal north cluster report (Climate change in Australia projections for Australia's natural resource management regions: Cluster reports). CSIRO and Bureau of Meteorology, Australia. Retrieved from plan.northerngulf.com. $\mathrm{au} / \mathrm{wp}$-content/uploads/2015/11/Monsoonal-North-regional-climate-changeprojections-report.pdf

Nicholls, N., McBride, J. L. \& Ormerod, R. J. (1982). On predicting the onset of the Australian wet season at Darwin. Monthly Weather Review, 110, 14-17.

O'Brien, C. (2014). Imported understandings: Calendar, weather and climate in tropical Australia, 1870s-1940s. In J. Beattie, E. O'Gorman \& M. Henry (Eds), Climate, science and colonization (pp. 195-211). New York, NY: Palgrave Macmillan.

O’Brien, C. (2016). Rethinking seasons: Changing climate, changing time. In T. Bristow \& T. Ford (Eds), A cultural history of climate change (pp. 38-54). New York, NY: Routledge.

Robin, L. (2007). How a continent created a nation. Sydney, NSW: UNSW Press.

Taylor, T. G. (1918). The Australian environment (especially as controlled by rainfall). Melbourne, Vic.: Government printer.

Tickell, S. (2005, 1 April). Groundwater resources of the Tindall Limestone. Darwin, NT: Department of Natural Resources, the Environment and the Arts.

Verma, M. (2003). 1:250,000 hydrogeological map of Darwin Harbour, DIPE. In T. Haig \& S. Townsend, An understanding of the groundwater and surface water hydrology of the Darwin Harbour Plan of Management Area. Proceedings of the Darwin Harbour Public Presentations. Darwin: Northern Territory Government. 
This text is taken from Leading from the North: Rethinking Northern Australia Development, edited by Ruth Wallace, Sharon Harwood, Rolf Gerritsen, Bruce Prideaux, Tom Brewer, Linda Rosenman and Allan Dale, published 2021 by ANU Press, The Australian National University, Canberra, Australia. 